\title{
A DESINSTITUCIONALIZAÇÃO DE CRIANÇAS E ADOLESCENTES, COMO GARANTIA DO DIREITO À CONVIVÊNCIA FAMILIAR
}

Loiany Sá Pinheiro

Aluna do curso de Direito da FA7.

loiany_hotmail.com

Sumário: Introdução. 1. Referencial Teórico.

Considerações finais. Referências.

Resumo: O presente trabalho aborda a institucionalização de crianças e adolescentes no Brasil e o não atendimento da excepcionalidade e da provisoriedade da medida protetiva em comento - o acolhimento institucional, levando os referidos sujeitos de direitos a terem seu direito à convivência familiar violado, obtendo um consequente prejuízo em sua formação psíquica, moral, espiritual e social, tendo em vista que se trata de seres em desenvolvimento. Assim, apresentase a proteção integral contemplada pelas crianças e pelos adolescentes na Constituição Federal de 1988 e no Estatuto da Criança e do Adolescente e uma análise de sua efetividade quanto à aplicação da medida protetiva de acolhimento institucional, em casos de violação de algum direito tutelado pelo ECA, e quanto à ocorrência do caminho inverso da institucionalização - a desinstitucionalização, visando preferencialmente à reintegração familiar e, na impossibilidade desta, à colocação em família substituta, por meio de guarda, tutela ou adoção. Busca-se apontar um olhar mais sensível àqueles que estão privados da convivência familiar e que são muitas vezes esquecidos nos abrigos, por conta de uma negligência do Poder Público no que diz respeito às políticas públicas voltadas ao público infanto-juvenil e às melhorias necessárias no âmbito do Judiciário, de modo que se pudesse atribuir prioridade absoluta aos processos atinentes às crianças e aos adolescentes.

Palavras-Chave: Acolhimento Institucional. Proteção Integral. Direito à Convivência Familiar. Desinstitucionalização.

\section{INTRODUÇ̃̃O}

Tem-se como objetivo geral deste artigo apresentar a desinstitucionalização, que pode ocorrer através da reintegração familiar ou da colocação em família substituta, de crianças e adolescentes que se encontram em abrigos, como uma necessidade para um real estabelecimento do caráter provisório e excepcional da medida de proteção de acolhimento institucional e, sobretudo, para a efetivação do direito à convivência familiar.

Especificamente, objetiva-se: abordar a proteção legal dada às crianças e aos adolescentes, fundada na Doutrina da Proteção Integral; analisar o acolhimento institucional e seus parâmetros legais, contrapondo-os à realidade; e por fim, fomentar uma maior preocupação por parte do Poder Público e da sociedade, no que tange à busca pela efetivação do direito à convivência familiar de crianças e adolescentes institucionalizados. 
As hipóteses levantadas neste trabalho foram investigadas, bem como analisadas, por meio do método de abordagem dedutivo, de pesquisas do tipo: bibliográfica, tendo em vista que foram lidos livros que tratam sobre o assunto em foco, sobretudo na área do Direito da Criança e do Adolescente, bem como artigos, dissertações, jornais e outros tipos de publicação envolvendo a temática analisada; e documental, através de leis e projetos de lei, resoluções, portarias, levantamentos estatísticos, pesquisas via internet e outros.

Quanto aos seus objetivos, a pesquisa foi: descritiva, buscando observar, descrever, registrar, analisar e explicar os fatos; exploratória, com o intuito de aprofundar o estudo do problema por meio de levantamento bibliográfico; e explicativa, procurando apontar as razões para a ocorrência do fenômeno e possíveis soluções.

Quanto à forma de abordagem, a pesquisa mostrou-se qualitativa, uma vez que se buscou compreender e explicar as informações obtidas em pesquisas quantitativas de outras pessoas.

\section{REFERENCIAL TEÓRICO}

\subsection{Abordagem geral da CF e do ECA}

A Constituição Federal de 1988, inaugurou uma nova forma de tratar normativamente a infância e a juventude. Estando já no espírito da elaboração da Convenção Internacional dos direitos da criança e do adolescente - CDC, aprovada pela Assembleia Geral das Nações Unidas em 1989, o legislador constituinte brasileiro, nos arts. 227 e 228, instituiu a proteção integral a ser concedida à criança e ao adolescente, com absoluta prioridade. $\mathrm{O}$ Brasil ratificou a referida Convenção em 1990 e, no mesmo ano, internalizou sua essência na legislação nacional, criando o Estatuto da Criança e do Adolescente.

O Estatuto da Criança e do Adolescente - ECA (lei $n^{\circ}$ 8.069/90) regulamenta, conforme seu art. $1^{\circ}$, a mencionada proteção integral, trazendo em seu bojo previsões diversas relacionadas à sua efetivação, tais como sobre os direitos fundamentais, as políticas de atendimento, as medidas de proteção, entre outras. Com esse estatuto, a Doutrina da Situação Irregular, que apresentava um caráter filantrópico e assistencial e tinha como foco as situações de abandono e delinquência, deu lugar, de fato, à Doutrina da Proteção integral, de natureza garantista, o que significa que crianças e adolescentes passaram a ser tratados como sujeitos de direitos, independentemente de estarem ou não em situação de risco ou à margem da sociedade.

Coroar uma doutrina garantista significa que não se trata mais apenas de definir previamente situações e intervir na ocorrência delas buscando uma solução, considerando o "menor" como mero objeto de proteção, porém, quer dizer que ele é portador de inúmeros direitos, a serem garantidos devido à peculiar condição da criança e do adolescente como pessoa em desenvolvimento.

Com a Doutrina da Proteção Integral, o ordenamento jurídico brasileiro passou a ter um Direito da Criança e do Adolescente, em substituição ao Direito do Menor. Foram assegurados constitucionalmente os direitos à vida, à saúde, à alimentação, à educação, ao lazer, à profissionalização, à cultura, à dignidade, ao respeito, à liberdade e à convivência familiar e comunitária, conforme o art. 227, caput, da CF. Há uma responsabilidade conjunta por parte da família, da sociedade e do Estado, no que diz respeito à efetivação desses direitos. Nesse sentido, extrai-se: 


\begin{abstract}
A doutrina da proteção integral, por outro lado, rompe o padrão pré-estabelecido e absorve os valores insculpidos na Convenção dos Direitos da Criança. Pela primeira vez, crianças e adolescentes titularizam direitos fundamentais, como qualquer ser humano. Passamos, assim, a ter um Direito da Criança e do Adolescente, em substituição ao Direito do Menor, amplo, abrangente, universal e, principalmente, exigível (MACIEL, et ali, 2010, p.14).
\end{abstract}

Vários princípios compõem a supracitada doutrina e expressam os valores mais relevantes do ECA. Dentre eles, três são gerais e norteiam todo o estatuto: o Princípio da prioridade absoluta, o Princípio do melhor interesse e o Princípio da municipalização.

O primeiro está estabelecido no art. 227, da CF, e no art. $4^{\circ}$, da lei 8.069/90, e atribui primazia plena, irrestrita às crianças e aos adolescentes em quaisquer situações, vejamos:

Seja no campo judicial, extrajudicial, administrativo, social ou familiar, o interesse infanto-juvenil deve preponderar. Não comporta indagações ou ponderações sobre o interesse a tutelar em primeiro lugar, já que a escolha foi realizada pela nação através do legislador constituinte (MACIEL et al., 2010, p. 20).

O segundo princípio leva em conta o melhor interesse da criança ou do adolescente, visando à adoção da medida que os favoreça. Dessa forma, em litígios de natureza familiar, em que se disputa a guarda da criança, por exemplo, não se pode perder de vista que a mais afetada ao final de tudo será a própria criança, por isso ela deverá ficar com quem possa lhe oferecer proteção, amor, condições sociais dignas, educação, enfim, o melhor para ela.

O terceiro princípio, o da municipalização, preceitua a descentralização administrativa das políticas de atendimento dirigidas aos referidos titulares de direitos, facilitando a implementação delas, vez que se encontra a entidade municipal mais próxima da realidade local, e também facilitando a fiscalização por parte da população. Explica-se, assim, o importante papel do Conselho Tutelar, que é o de promover ações com o intuito de defender direitos e interesses infanto-juvenis, no âmbito municipal.

Dentre os inúmeros direitos fundamentais, o legislador constituinte elencou no art. 227 aqueles que se mostram essenciais ao bom desenvolvimento da criança e do adolescente, já tendo sido citados anteriormente. Em análise breve, discorrer-se-á sobre cada um.

O direito à vida é o mais importante de todos, pois sem ele não se poderia cogitar da existência dos demais. Vai além de uma simples questão de sobrevivência da criança ou do adolescente, constituindo na verdade um direito de viver com dignidade.

$\mathrm{O}$ direito à saúde, tanto física, quanto mental e social, deve ser assegurado pela família, comunidade e poder público. Se a família não puder, de alguma forma, garantir essa saúde, por ausência de condições de oferecer uma alimentação adequada ou até condições de higiene adequadas, caberá ao poder público suprir essa carência. $\mathrm{O}$ direito à alimentação, assim, está ligado ao direito à saúde.

Quanto ao direito à educação, o art. 205 da Constituição Federal enuncia claramente o seguinte:

A educação, direito de todos e dever do Estado e da família, será promovida e incentivada com a colaboração da sociedade, visando ao pleno desenvolvimento da pessoa, seu preparo para o exercício da cidadania e sua qualificação para o trabalho.

O direito à cultura e ao lazer também foram elencados, tendo em vista sua importância para o desenvolvimento intelectual e social, permitindo que a criança e o adolescente ampliem seus conhecimentos e aprendam a se relacionarem com outras pessoas, além de poderem espairecer, descansando a mente. 
O direito à profissionalização faz parte do processo de formação do adolescente, que está prestes a ingressar no mercado de trabalho. Devem ser respeitadas algumas restrições, vez que o adolescente goza de um regime especial de trabalho, sendo, por exemplo, vedado o trabalho do menor de 16 anos, salvo na condição de aprendiz a partir de 14 anos.

$\mathrm{O}$ respeito e a dignidade estão intrinsecamente ligados e a observância de um leva à ocorrência do outro. É o direito de não sofrer qualquer tipo de violência e discriminação. Direito de não mais ser tratado como "menor", expressão que por muito tempo trouxe em si uma conotação pejorativa.

$\mathrm{O}$ direito à liberdade, além ser o direito de ir e vir, engloba também a liberdade de opinião, expressão, crença e culto religioso, liberdade para brincar, entre outras. Todavia, não concede à criança e ao adolescente absoluta autodeterminação, de modo a fazerem o que bem entenderem. Esse direito deve ser exercido sempre em seu favor, caso contrário, os pais e/ou o poder público devem intervir.

Por fim, aborda-se o direito à convivência familiar e comunitária - sendo a primeira foco do presente trabalho, que, além de um direito, chega a ser uma necessidade, sobretudo, da criança. É o direito da criança e do adolescente de viver junto à família natural, num ambiente que lhes ofereça segurança, afeto e tranquilidade, com oportunidade de se relacionar com pessoas da vizinhança, fazer amizades na escola, frequentar ambiente religioso, enfim, ter uma vivência também comunitária. Não sendo possível a permanência na família de origem, o menor, termo agora empregado no sentido técnico - menoridade, deverá ser colocado numa família substituta, para que não venha a ser privado da convivência familiar.

Reafirmando o que foi dito, assevera Wilson Donizeti Liberati:

A ausência da família, a carência de amor e de afeto comprometem o desenvolvimento da criança e do adolescente. A família é, portanto, o agente socializador por excelência do ser humano. [...] Esse direito é personalíssimo, intransferível, inalienável e imprescritível (LIBERATI, 2011, p. 26).

Na mesma linha do pensamento suso alinhado, aduz-se:

Desse modo, a família, além de ser o meio primário que propicia as primeiras e elementares noções de convivência social, ela é principalmente, também, o meio que possibilita o desenvolvimento de todas as faculdades físicas, psíquicas, morais e espirituais da criança e do adolescente, no sentido de que, por mais que muitos desses conteúdos (sociais, morais, intelectuais e espirituais) advenham do contato com outras instâncias, a família é responsável, por assim dizer, pelo cultivo da terra onde as sementes serão lançadas. (VERONESE apud FACHINETTO, 2009, p. 65).

\subsection{O Acolhimento institucional, a desinstitucionalização e o direito à convivência familiar}

Antes da colocação em família substituta, o ECA prevê medidas de proteção a serem aplicadas à criança e ao adolescente que tenham algum direito ameaçado ou violado, por ação ou omissão da sociedade ou do Estado, por falta, omissão ou abuso dos pais ou responsável, ou ainda em razão de sua conduta, de acordo com o art. 98. Referidas medidas estão previstas no art. 101 e serão aplicadas pela autoridade judiciária ou pelo Conselho Tutelar, tendo como objetivo retirar a criança e o adolescente da situação de risco pessoal e social que por ventura nela se encontrem, salvaguardando seus direitos.

Dentre as medidas enumeradas no rol exemplificativo do art. 101, é dado destaque à estabelecida no inciso VII, denominada acolhimento institucional pela lei $\mathrm{n}^{\circ} 12.010 / 09$, tendo 
sido chamada antes desta, de medida de abrigo. Trata-se de uma providência que enseja a retirada da criança ou do adolescente de sua família e o seu encaminhamento a uma entidade de acolhimento institucional, em razão muitas vezes de abandono, maus-tratos ou abuso sexual.

Essa medida deve apresentar, segundo o $\S 1^{\circ}$ do art. 101, duas importantes características: a provisoriedade e a excepcionalidade. A primeira consiste em permanecer no abrigo aquele que recebe a medida por tempo estritamente necessário, não podendo ultrapassar o período de dois anos, salvo por comprovada necessidade, conforme o $\S 2^{\circ}$ do art. 19. Assim, a criança ou o adolescente não corre, pelo menos na seara legal, o risco de ter mais um direito violado: o da convivência familiar. A cada seis meses, sua situação deve ser reavaliada, visando sempre à reintegração familiar, preferencialmente, ou à colocação em família substituta - $\S 1^{\circ}$ do art.19. A segunda característica consiste em somente adotar a medida quando não houver mais possibilidade alguma de manutenção da criança ou do adolescente na família natural, já tendo sido esgotadas outras providências protetivas, não havendo também possibilidade de colocação imediata em família substituta.

O ECA proporcionou, dessa maneira, uma nova roupagem à institucionalização no Brasil, vez que esta tem caráter transitório, não constituindo um fim em si mesma. Nesse sentido, observa-se:

Portanto, não tem mais o objetivo de limpar as ruas ou segregar/excluir os indesejáveis de outrora, mas sim de cumprir a missão de garantir os direitos fundamentais das pessoas humanas crianças e adolescentes que estão em situação de vulnerabilidade pessoal ou social (FACHINETTO, 2009, p. 72).

A competência para aplicação da medida em análise é exclusiva da autoridade judiciária, visto que implica o afastamento da criança ou do adolescente do convívio familiar, conforme o $\S 2^{\circ}$ do art. 101. Há exceção, contudo, prevista no art. 93 do estatuto, permitindo que, em caráter excepcional e de urgência, crianças e adolescentes sejam acolhidas sem a prévia autorização judicial.

Na seara legal, portanto, a doutrina da proteção integral ganhou forma realmente. O problema é que, na prática, não se tem conseguido dar efetividade à provisoriedade da institucionalização, afetando o desenvolvimento das crianças e dos adolescentes abrigados, que se tornam vítimas novamente, pelo fato de terem seu direito à convivência familiar desrespeitado. Uma institucionalização prolongada acarreta sérias consequências, como elucida Sergio Luiz Kreuz:

Por melhor equipada que seja uma instituição, sob o aspecto físico e humano, o longo tempo de acolhimento, além de produzir o esfacelamento dos laços familiares (com a família biológica), prejudica sua estimulação, priva a criança do convívio social, retardando a socialização e seu desenvolvimento (2012, p. 54).

Em 2003, o Instituto de Pesquisa Econômica Aplicada (IPEA) realizou um estudo nacional sobre a situação de crianças e adolescentes encontradas em abrigos que receberam recursos do Governo Federal. Foram avaliadas 589 entidades de acolhimento institucional, e constatou-se que mais da metade $(55,2 \%)$ das cerca de 20 mil crianças e adolescentes encontrados estava nos abrigos há um período que variava entre sete meses e cinco anos. A parcela mais significativa $(32,9 \%)$, porém, estava nos abrigos há um período entre dois e cinco anos, $13,3 \%$ entre seis e dez anos e 6,4\% por mais de dez anos, ultrapassando o prazo estipulado pelo ECA e infringindo a temporariedade da medida de acolhimento institucional. Além disso, 
a grande maioria dos abrigados tinha família $(86,7 \%)$ e dentre os motivos que os levaram aos abrigos, a pobreza foi a mais citada $(24,2 \%)$, depois o abandono $(18,9 \%)$, a violência doméstica $(11,7 \%)$, a dependência química dos pais ou responsáveis, incluindo alcoolismo $(11,4 \%)$, a vivência de rua $(7,0 \%)$ e a orfandade $(5,2 \%)$. Vale ressaltar que o principal motivo apontado, a pobreza, não constitui causa de abrigamento, a não ser que estivesse conjugada com outros fatores aceitos, pois há a previsão no ECA de inclusão da família em programas oficiais de auxílio.

Destarte, é possível observar a necessidade de serem implementadas políticas públicas destinadas à promoção, proteção e defesa do direito fundamental à convivência familiar, dando efetividade ao Plano Nacional aprovado pelo CONANDA - Conselho Nacional dos Direitos da Criança e do Adolescente e pelo CNAS - Conselho Nacional de Assistência Social, com esse intuito, em dezembro de 2006, e que tem como uma de suas diretrizes a garantia dos princípios de excepcionalidade e provisoriedade dos programas de famílias acolhedoras e de acolhimento institucional de crianças e adolescentes.

É preciso que essas crianças e esses adolescentes trilhem um caminho rumo à desinstitucionalização, inadmitindo-se que sejam simplesmente "esquecidas" nas instituições e privadas do direito à convivência familiar.

\footnotetext{
Nesse contexto, o resgate e valorização do direito à convivência familiar e comunitária, como direito fundamental, pressupõe que a família - não apenas na sua concepção estritamente jurídica - deve ser vista como local ideal de criação dos filhos, importando, concomitantemente, em uma cruzada pela desinstitucionalização de crianças e adolescentes (FACHINETTO, 2009, p. 57).
}

Nas palavras de Wilson Donizeti Liberati (apud FACHINETTO, 2009, p. 74), "[...] perpetuar a criança na instituição é enterrar-lhe o futuro, é sufocar-lhe o desejo de descortinar horizontes".

\section{CONSIDERAÇões FINAIS}

Em décadas passadas, quando ainda estávamos sob a égide da Doutrina da Situação Irregular, crianças e adolescentes não eram vistos como titulares de direitos, constituindo apenas objetos de intervenção do Estado, em situações de delinquência e abandono. Portanto, grande era o número desses sujeitos, que ficavam confinados em instituições, recebendo um tratamento repressivo ou, no máximo, assistencialista. Com o advento da Constituição Federal de 1988, houve uma mudança de paradigma ao ser atribuída a proteção integral à criança e ao adolescente. Posteriormente, em 1990, o ECA consolidou a Doutrina da Proteção Integral, não permitindo mais que se fale em uma institucionalização indiscriminada.

Dessa maneira, muito já evoluiu o ordenamento jurídico brasileiro, no que tange ao tratamento dado a esses seres em desenvolvimento. Não se pode, entretanto, estagnar essa evolução, pois ainda não se conseguiu efetivar plenamente a referida proteção integral, tendo em vista a questão ora suscitada, sobre a não provisoriedade da medida de abrigamento e o consequente desrespeito ao direito à convivência familiar.

Frisa-se, assim, que o acolhimento institucional ao mesmo tempo em que possibilita a preservação de alguns direitos da criança e do adolescente, como a integridade física, psíquica e moral, por exemplo, retira desses titulares o direito à convivência familiar, por tempo muitas vezes indeterminado. O que era pra ser uma solução, então, acaba gerando uma situação preocupante em nosso país: o número de crianças e adolescentes institucionalizados, sem uma garantia de 
reintegração à família de origem ou de inserção numa família substituta e sofrendo, por conta da institucionalização prolongada, sérias consequências.

É preciso que sejam observados de fato o princípio da prioridade absoluta e o princípio do melhor interesse, no que tange à efetivação dos direitos da criança e do adolescente, bem como os princípios que regem a aplicação das medidas protetivas, sobretudo o da prevalência da família, estabelecido no art. 100, X, do Estatuto da Criança e do Adolescente.

Enquanto as famílias, a sociedade e o Estado não tomarem consciência da gravidade que é simplesmente esquecerem crianças e adolescentes em instituições de acolhimento ou, em outras palavras, consentirem com a institucionalização prolongada, e não buscarem solucionar o problema de forma conjunta, esses sujeitos continuarão sendo duplamente vitimados: primeiro por suas próprias famílias, posteriormente pelo Estado.

A desinstitucionalização é uma necessidade para adequar a realidade infanto-juvenil brasileira aos moldes do Estatuto da Criança e do Adolescente, uma vez que se fala de titulares de direitos e não mais de menores infratores e/ou abandonados, apenas, que eram colocados nos abrigos ou orfanatos para se "limpar" as ruas. E para que a desinstitucionalização possa acontecer faticamente, as políticas públicas devem ser revistas, as varas da Infância e da Juventude precisam ser mais eficientes, sendo inadmissível que um juiz dessa área responda por várias varas ao mesmo tempo, como acontece, e os processos que tenham crianças e adolescentes como sujeitos devem gozar de prioridade absoluta.

\section{REFERÊNCIAS}

BRASIL, Vade Mecum, 6 ed. São Paulo: Saraiva, 2011.

. Decreto $n^{\circ}$ 99.970, de 21 de novembro de 1990, Convenção sobre os Direitos da Criança, disponível em: http://www.planalto.gov.br/ccivil_03/decreto/1990-1994/D99710.htm. Acesso em 15.mar.2012.

- Projeto de lei, $\mathbf{n}^{0}$ 1432/2011 - dispondo sobre a adoção tardia, disponível em. Acesso em 02.abr.2012.

- Menor recolhida em abrigo para adoção deve ser devolvida à mãe biológica, Superior Tribunal de Justiça, disponível em: http://www.stj.gov.br/portal_stj/publicacao/engine.wsp?tmp. area $=398 \&$ tmp.texto $=105302$. Acesso em 11.abr.2012.

FACHINETTO, Neidemar José. O direito à convivência familiar e comunitária: contextualizando com as políticas públicas (in)existentes, Porto Alegre: Livraria do Advogado, 2009.

GONÇALVES, Carlos Roberto. Direito civil brasileiro, Vol. VI - direito de família, 7 ed. São Paulo: Saraiva, 2010.

KREUZ, Sergio Luiz. Direito à convivência familiar da criança e do adolescente: direitos fundamentais, princípios constitucionais e alternativas ao acolhimento institucional. Curitiba: Juruá, 2012.

LIBERATI, Wilson Donizeti. Direito da criança e do adolescente. 5 ed. São Paulo: Rideel, 2011.

MACIEL, Kátia Regina Ferreira Lobo Andrade (Coord.), et ali, Curso de direito da criança e do adolescente - aspectos teóricos e práticos, $3^{\mathrm{a}}$ tiragem, 4 ed. Rio de Janeiro: Lumen Juris, 2010. 
$O$ direito de ser adolescente: Oportunidade para reduzir vulnerabilidades e superar desigualdades / Fundo das Nações Unidas para a Infância. - Brasília, DF: UNICEF, 2011, disponível em: http://www.unicef. org/brazil/pt/resources_22246.htm. Acesso em 19.abr.2012.

SILVA, Enid Rocha Andrade. Levantamento nacional de abrigos para crianças e adolescentes da rede SAC - IPEA, disponível em: http://portaldovoluntario.v2v.net/ documents/0000/0189/109726162757.pdf. Acesso em 22.mar.2012.

\section{THE DEINSTITUTIONALIZATION OF CHILDREN AND ADOLESCENTS AS GUARANTEE OF THE RIGHT TO FAMILY LIFE}

Abstract: This paper discusses the institutionalization of children and adolescents in Brazil and the fulfillment of the requirements of exceptionality and temporariness of the protective measure under discussion - the institucional shelter, leading those individuals to have their right to family life violated, getting a consequent prejudice in their mental, moral, spiritual and social training, in view of the fact that it's about developing human beings. Thus, through this work, we present the full protection contemplated by children and adolescents in the 1988 Federal Constitution and the Statute of Children and Adolescents and a review of its effectiveness in applying the protective measure of institutional care in cases of violation of any law overseen by the ECA, and occurrence of the reverse path of institutionalization - deinstitutionalization, preferably aimed at family reintegration and, failing this, the placement in a foster family, through custody, guardianship or adoption. The aim is to point out a more sensitive way to look at those who are deprived of family companionship and that are often overlooked in shelters, due to the negligence of the Government with regards to public policies aimed at juvenile people and at the necessary improvements within the judiciary, so that they could give high priority to the procedures relating to children and teenagers.

Keywords: Institutional Shelter. Full Protection. Right to Family Life. Deinstitutionalization. 